\title{
SPO mirror plate production and coating
}

Landgraf, Boris; Babi, Ljubiša; Barrière, Nicolas M.; Bayerle, Alex; Castiglione, Luigi; Collon, Maximilien J.; Eenkhoorn, Noë; Girou, David; Günther, Ramses; Hauser, Enrico

Total number of authors:

49

Published in:

Proceedings of SPIE

Link to article, DOI:

$10.1117 / 12.2594234$

Publication date:

2021

Document Version

Publisher's PDF, also known as Version of record

Link back to DTU Orbit

Citation (APA):

Landgraf, B., Babi, L., Barrière, N. M., Bayerle, A., Castiglione, L., Collon, M. J., Eenkhoorn, N., Girou, D., Günther, R., Hauser, E., Jenkins, Y., Keek, L., Okma, B., Serano, G. M., Thete, A., Vacanti, G., Verhoeckx, S., Vervest, M., Voruz, L., ... Ball, K. (2021). SPO mirror plate production and coating. In S. L. O'Dell, J. A. Gaskin, \& G. Pareschi (Eds.), Proceedings of SPIE: Optics for EUV, X-Ray, and Gamma-Ray Astronomy X [1182207] SPIE - International Society for Optical Engineering. Proceedings of SPIE - The International Society for Optical Engineering Vol. 11822 https://doi.org/10.1117/12.2594234

\section{General rights}

Copyright and moral rights for the publications made accessible in the public portal are retained by the authors and/or other copyright owners and it is a condition of accessing publications that users recognise and abide by the legal requirements associated with these rights.

- Users may download and print one copy of any publication from the public portal for the purpose of private study or research.

- You may not further distribute the material or use it for any profit-making activity or commercial gain

- You may freely distribute the URL identifying the publication in the public portal 


\title{
SPO mirror plate production and coating
}

Boris Landgraf*a Ljubiša Babića ${ }^{a}$, Nicolas M. Barrière ${ }^{\mathrm{a}}$, Alex Bayerle ${ }^{\mathrm{a}}$, Luigi Castiglione ${ }^{\mathrm{a}}$, Maximilien J. Collon ${ }^{a}$, Noë Eenkhoorn ${ }^{a}$, David Girou ${ }^{a}$, Ramses Günther ${ }^{\mathrm{a}}$, Enrico Hauser ${ }^{\mathrm{a}}$, Yvette Jenkins $^{\mathrm{a}}$, Laurens Keek ${ }^{\mathrm{a}}$, Ben Okma ${ }^{\mathrm{a}}$, Gregorio Mendoza Serano ${ }^{\mathrm{a}}$, Aniket Thete ${ }^{\mathrm{a}}$, Giuseppe Vacanti ${ }^{\mathrm{a}}$, Sjoerd Verhoeckx ${ }^{\mathrm{a}}$, Mark Vervest ${ }^{\mathrm{a}}$, Luc Voruz ${ }^{\mathrm{a}}$, Marco W. Beijersbergen ${ }^{\mathrm{a}}$, Marcos Bavdaz ${ }^{\mathrm{b}}$, Eric Wille $^{\mathrm{b}}$, Ivo Ferreira ${ }^{\mathrm{b}}$, Sebastiaan Fransen ${ }^{\mathrm{b}}$, Brian Shortt ${ }^{\mathrm{b}}$, Mark Olde Riekerink ${ }^{\mathrm{c}}$, Jeroen Haneveld ${ }^{\mathrm{c}}$, Arenda Koelewijn ${ }^{c}$, Maurice Wijnperle ${ }^{c}$, Jan-Joost Lankwarden ${ }^{\mathrm{c}}$, Bart Schurink ${ }^{\mathrm{c}}$, Ronald Start ${ }^{\mathrm{c}}$, Coen van Baren $^{\mathrm{d}}$, Paul Hieltjes ${ }^{\mathrm{d}}$, Jan Willem den Herder ${ }^{\mathrm{d}, \mathrm{j}}$, Evelyn Handick ${ }^{\mathrm{e}}$, Michael Krumrey ${ }^{\mathrm{e}}$, Miranda Bradshaw $^{\mathrm{f}}$, Vadim Burwitz ${ }^{\mathrm{f}}$, Sonny Massahi ${ }^{\mathrm{g}, \mathrm{k}}$, Sara Svendsen ${ }^{\mathrm{g}}$, Desirée Della Monica Ferreira ${ }^{\mathrm{g}}$, Finn E. Christensen ${ }^{\mathrm{g}, \mathrm{k}}$, Giuseppe Valsecchi ${ }^{\mathrm{h}}$, Geeta Kailla ${ }^{\mathrm{i}}$, Gavin Phillips ${ }^{\mathrm{i}}$, William Mundon ${ }^{\mathrm{i}}$, Ian Chequer ${ }^{\mathrm{i}}$, Kevin Ball ${ }^{\mathrm{i}}$

a cosine Research B.V., Oosteinde 36, 2361 HE Warmond, The Netherlands

${ }^{\mathrm{b}}$ European Space Agency, ESTEC, Keplerlaan 1, PO Box 299, 2200 AG Noordwijk, The Netherlands

${ }^{\mathrm{c}}$ Micronit B.V., Colosseum 15, 7521 PV Enschede, The Netherlands

d SRON Leiden, Niels Bohrweg 4, 2333 CA Leiden, The Netherlands

${ }^{e}$ Physikalisch-Technische Bundesanstalt (PTB), Abbestr. 2-12, 10587 Berlin, Germany

${ }^{\mathrm{f}}$ MPI f. extraterrestrische Physik, Giessenbachstrasse 1, 85748 Garching, Germany

${ }^{g}$ DTU Space, Technical University of Denmark, Building 327, DK - 2800 Kgs. Lyngby, Denmark

${ }^{\mathrm{h}}$ Media Lario S.r.l., Località Pascolo, 23842 Bosisio Parini(LC), Italy

${ }^{i}$ Teledyne e2v, 106 Waterhouse Lane, Chelmsford, Essex CM1 2QU, United Kingdom

${ }^{\mathrm{j}}$ Anton Pannekoek Institute, University of Amsterdam, 1090 GE Amsterdam, the Netherlands

${ }^{\mathrm{k}}$ CHEXS, Diplomvej 373B, 2800 Kgs. Lyngby, Denmark

\begin{abstract}
The Silicon Pore Optics (SPO) technology has been established as a new type of X-ray optics enabling future X-ray observatories such as Athena and ARCUS. SPO is being developed at cosine together with the European Space Agency (ESA) and academic as well as industrial partners. The SPO modules are lightweight, yet stiff, high-resolution X-ray optics, allowing missions to reach a large effective area of several square meters. These properties of the optics are mainly linked to the mirror plates consisting of mono-crystalline silicon. Silicon is rigid, has a relatively low density, a very good thermal conductivity and excellent surface finish, both in terms of figure and surface roughness. For Athena, a large number of mirror plates are required, around 150,000 for the qualification model (QM) and flight model (FM) configurations. With the technology spin-in from the semiconductor industry, mass production processes can be employed to manufacture rectangular shaped SPO mirror plates in high quality, large quantity and at low cost. Within the last few years, several aspects of the SPO mirror plates have been reviewed and undergone further developments in terms of effective area, intrinsic behavior of the mirror plates and mass production capability. In view of flight model production, a second plate supplier has been added in addition to the first plate supplier. The paper provides an overview of the most recent plate design, metrology and production developments.
\end{abstract}

Keywords: X-ray optics, X-ray astronomy, silicon, wafer, stack, pore optics, X-ray telescopes, Athena, mass production, SPO, coating

*b.landgraf@cosine.nl; www.cosine.nl

Optics for EUV, X-Ray, and Gamma-Ray Astronomy X, edited by Stephen L. O'Dell,

Jessica A. Gaskin, Giovanni Pareschi, Proc. of SPIE Vol. 11822, 1182207 · C

2021 SPIE · CCC code: 0277-786X/21/\$21 - doi: 10.1117/12.2594234 


\section{INTRODUCTION}

This report details the current development status in the manufacturing of silicon mirror plates for the manufacture of Silicon Pore Optics (SPO) stacks [9, 11-17]. The plate manufacturing process begins with double-sided polished $300 \mathrm{~mm}$ wafers, and ends with diced, ribbed, wedged, and coated SPO plates which can be subsequently stacked to form an optical unit $[1,2]$. SPO stacks are currently fabricated using a combination of established semiconductor fabrication techniques and novel fabrication techniques specifically designed for ESA's Athena mission and NASA's ARCUS candidate mission $[6-8,10]$. The scientific requirements for Athena specify an angular resolution of five arc-seconds Half-Energy Width (HEW), and an energy-dependent effective area of up to $1.5 \mathrm{~m}^{2}$ [3-5]. All research and development effort to date has focused on achieving these goals.

SPO are being developed by a consortium of industrial partners which is coordinated by cosine and led by ESA. In 2007, Micronit B.V. joined the consortium and continued the process development of manufacturing silicon mirror plates for Athena. In 2016, Teledyne $\mathrm{e} 2 \mathrm{v}$ joined the consortium to increase manufacturing capacity. Both partners are implementing numerous process innovations in order to improve the quality of SPO plates while also reducing manufacturing cost.

In Figure 1, the process flow for production of SPO plates is depicted. The production of SPO plates consists of dicing $300 \mathrm{~mm}$ wafers into rectangular plates, ribbing the plates to create grooves along the optical axis and wedging the plates to create a thickness taper along the optical axis. After wedge manufacturing, a final processing step is necessary to boost the reflectivity of SPO mirror plates. Coating layer combinations of high- $Z$ and low-Z materials like iridium with silicon boron carbide, silicon carbide or carbon for the high and low-energy photons of Athena are suitable materials for obtaining the required X-ray reflectivity [21]. Patterning of the metal layer is needed to ensure bondability of the silicon mirror plates during the stack production process. Standard photolithographic techniques as applied in semiconductor industry are used to protect the bonding area of the mirror plates against metal deposition. After metal layer deposition, the excess metal which is coated in the bonding areas, can be removed by a lift-off process. As a last process step before stack production, SPO plates are cleaned using SC-1.

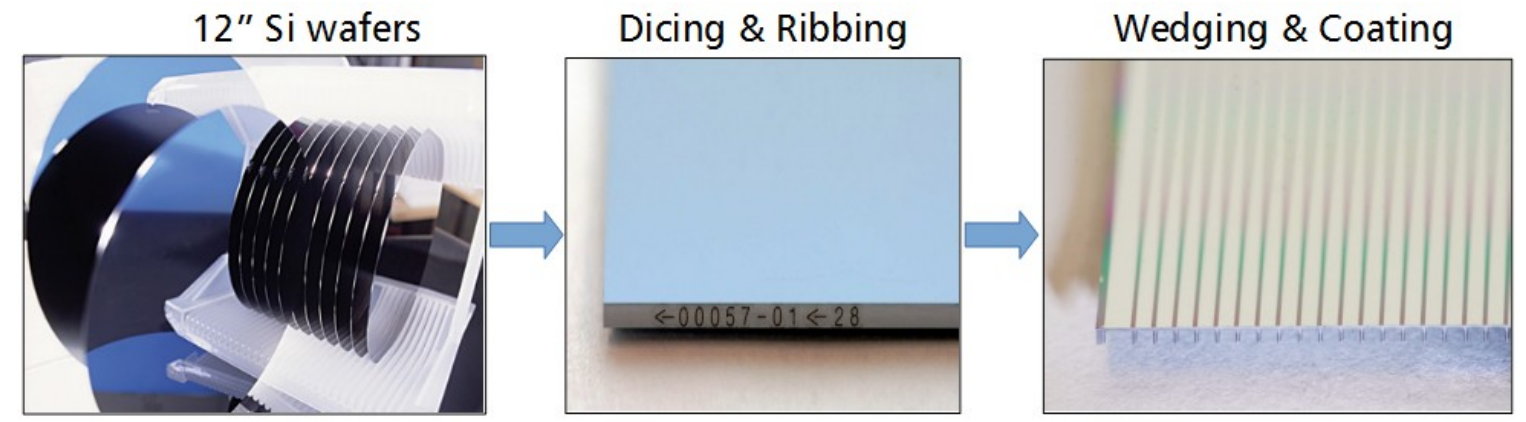

Figure 1. Overview of process flow for production of SPO mirror plates.

\section{PLATE GEOMETRY DEVELOPMENTS TOWARDS ATHENA PERFORMANCE GOALS}

During the current ongoing study phase B1, Athena's optics are being developed for a radial span from $250 \mathrm{~mm}$ up to $1500 \mathrm{~mm}$ (see Figure 2). We develop and test SPO at those two radii and in addition also at a middle radius of $737 \mathrm{~mm}$. Each radius demonstrates different aspects of the optics, from very long $(110 \mathrm{~mm})$ and narrow $(50 \mathrm{~mm})$ mirror plates at the innermost radius, to very short $(20 \mathrm{~mm})$, but wide $(102 \mathrm{~mm})$ plates of the outer mirror modules. The differences in aspect ratios bring an additional challenge for producing SPO plates, as those affect plate production throughput, yield and therefore price. In addition to those three existing plate types, we are now developing a new SPO plate type which is representative of the row- 8 of the latest Athena flight optics reference design with its 15 rings. The plan is to develop, to produce and to qualify row- 8 optics in time to demonstrate a Technology Readiness Level (TRL) of five for the SPO technology for the Mission Adoption Review (MAR). 

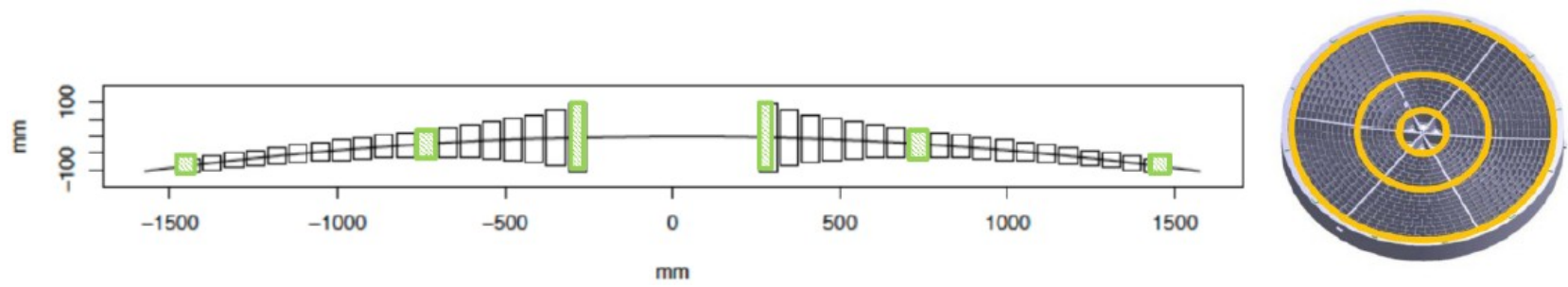

Figure 2. (Left) Cross section through the Athena optic. (Right) Athena optical bench as seen from the top. The radii for which SPO is being development are marked in green (left) and yellow (right). The innermost radius is $250 \mathrm{~mm}$, the outermost $1500 \mathrm{~mm}$ and as middle radius we chose $737 \mathrm{~mm}$.

We have started to develop row- 8 SPO plates with wider pores of about $2.2 \mathrm{~mm}$ and a thinner membrane thickness of about $0.11 \mathrm{~mm}$ in order to increase the effective area and reduce off-axis vignetting while keeping the impact on the angular resolution of the optics minimal. The process of making SPO plates with larger pores bears risks in terms of yield and price. The ribbing process of SPO plates is especially critical as large amounts of silicon material get removed mechanically. This creates stress inside of the silicon which can lead to cracking/breaking of the material. The investigations on varying pore width and height and the impact on the performance of the optics are ongoing.

The photographs in Figure 3 show the outer radius (top) and inner radius (bottom right) SPO plates with larger pores. A prototype of the new row- 8 mirror plate type is shown in the bottom left photograph in Figure 3 . Many different production process changes needed to be considered for this new SPO plate type. We developed new wafer layouts, ribbing and dicing programs, wet-processing carriers, masks for photolithography, transport carriers, coating carriers, new stacking equipment and updated various procedures for all the different production process steps.

Micronit B.V. has already produced about 600 row-8 SPO plates and increased the production yield to about $90 \%$. Besides further improving quality and yield, we are working on ways to increase production throughput with the given equipment in preparation for Athena flight production.
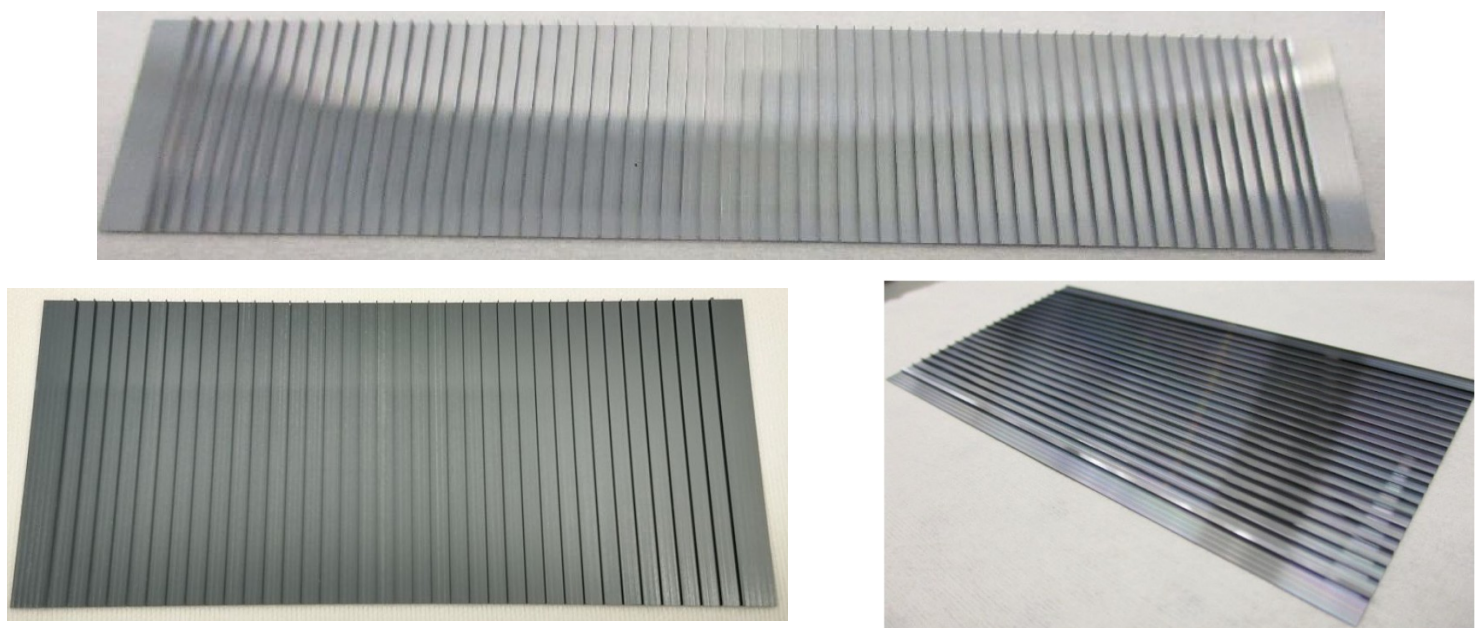

Figure 3. Photographs of the rib side of (top) outer radius, (bottom left) Athena's row- 8 and (bottom right) inner radius SPO plates.

In the past, Micronit B.V. has been using a reflectometer shown in the left photograph in Figure 4 to assess the $\mathrm{SiO}_{2}$ wedge quality on the reflective side of an SPO plate. The setup had an increased downtime due to its age and as such was a risk in terms of production stability. Based on a Total Thickness Variation (TTV) measurement system that cosine has available, which can measure both sides of SPO plates to determine the absolute wedge thickness, a dedicated and fully automated measurement setup has now been implemented also at Micronit B.V. This setup enables further improvements to be made in terms of yield, throughput and wedge quality and thereby improves the optical resolution of the Athena mirror. With this system, the wedge profiles on the reflective side of the plate, as well as on the ribbed side of the plate can be measured (rib side measurements were not possible with the previous system because of its larger focal 
spot), in order to ensure that the total wedge applied to the plate is within specifications. Until April 2020 the ribbed side was only measured at cosine, leading to a longer time feeding a wedge correction value back to Micronit B.V.
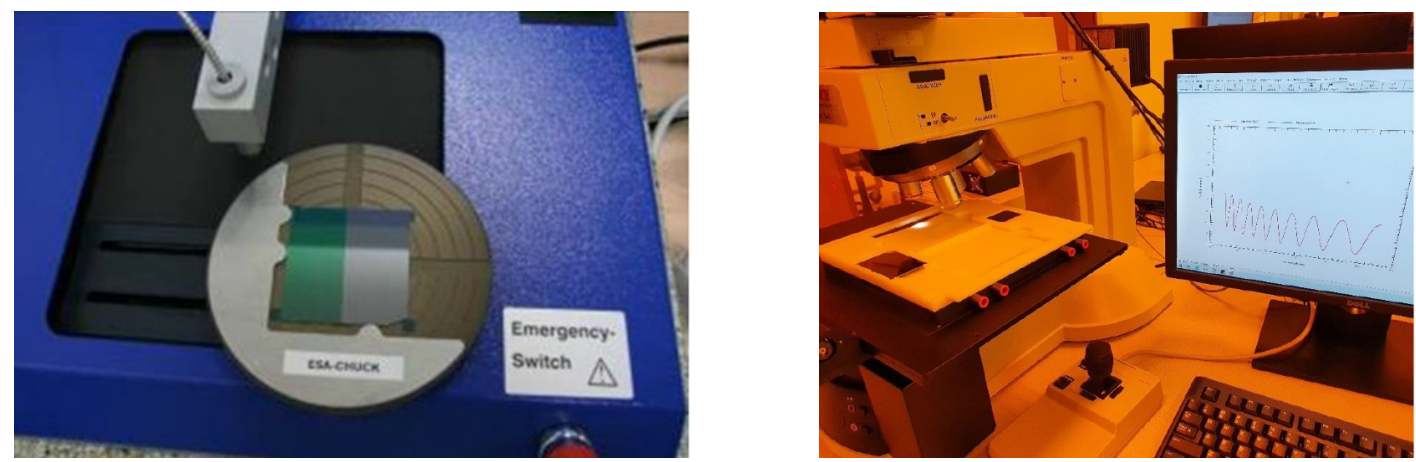

Figure 4. (left) Micronit's previous reflectometer. (right) Micronit's new TTV measurement system, a copy of the system cosine is using for characterization of SPO plates.

With the now implemented ribbed and reflective side $\mathrm{SiO}_{2}$ thickness measurements, Micronit B.V. can account for the difference in wedge angle between ribbed and reflective side and is since then able to produce SPO plates with a more accurate wedge angle. The residual error is less than three percent. The SPO plates produced with the new TTV measurement system show a significant improvement in wedge angle accuracy compared to previously produced SPO plates. The left and right graphs in Figure 5 shows wedge angles of produced SPO plates characterized with Micronit's previous reflectometer and their new TTV measurement system, respectively. The mean deviation is reduced from $3.1 \%$ to $0.4 \%$. As next steps, Micronit B.V. is going to further improve the wedge angle accuracy through plate production statistics and basic process control using their newly implemented TTV measurement system.
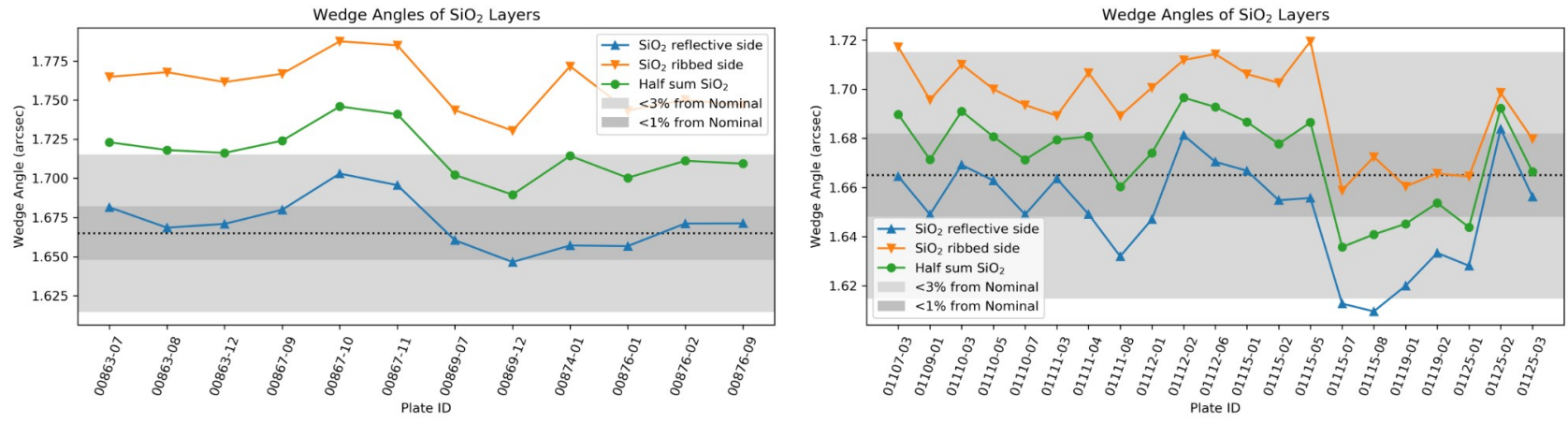

Figure 5. Wedge angle for the $\mathrm{SiO} 2$ layers of a series of SPO plates. The dotted line indicates the nominal value, the light gray and dark gray areas bound the $3 \%$ and $1 \%$ deviation from nominal value, respectively. The left graph presents wedge angles of produced SPO plates characterized with Micronit's previous reflectometer in 2019 and the right graph wedge angles of produced SPO plates characterized with their new TTV measurement setup in 2020.

The accuracy of the wedge in SPO plates is crucial for the resolution of the optics [20]. As a next improvement step, we have started to investigate Ion beam figuring (IBF) as a candidate to replace the wet-chemical wedge processing and to further improve the wedge accuracy. With first trials and as a proof of concept, we were already able to achieve with IBF the same accuracy of the wedge as with wet-chemical processing. IBF wedge processing has the potential of producing an even more accurate wedge because of its high process stability. The main advantages of using IBF compared to wetchemical wedge processing are to reduce recurring cost and complexity of the SPO plate production process by performing processing on wafer level instead of on plate level and having the following benefits for angular resolution and effective area.

- Potential to create more accurate $(<1 \%)$ wedge than with wet-chemical processing $(<3 \%)$

- Possible to further reduce initial TTV of silicon to $<<200 \mathrm{~nm}$ 
- Reduced variability in the value of the wedge, and smaller performance degradation with the number of stacked SPO plates

- Enables possibility of $0 /+2$ wedge configuration where the SPO plates in the primary stack of an optical unit have no wedge and the SPO plates in the secondary stack a double wedge of 6.68 arc-seconds. This configuration increases the effective area of the Athena optic by up to $10 \%$ compared to the current $-1 /+1$ wedge configuration baseline.

In November 2020, cosine ordered a fully automated $300 \mathrm{~mm}$ IBF system. A rendered drawing of the system is shown in Figure 6. The plan is to have the system installed before the end of 2021 and operational for IBF wedge processing of SPO plates at the beginning of 2022 .

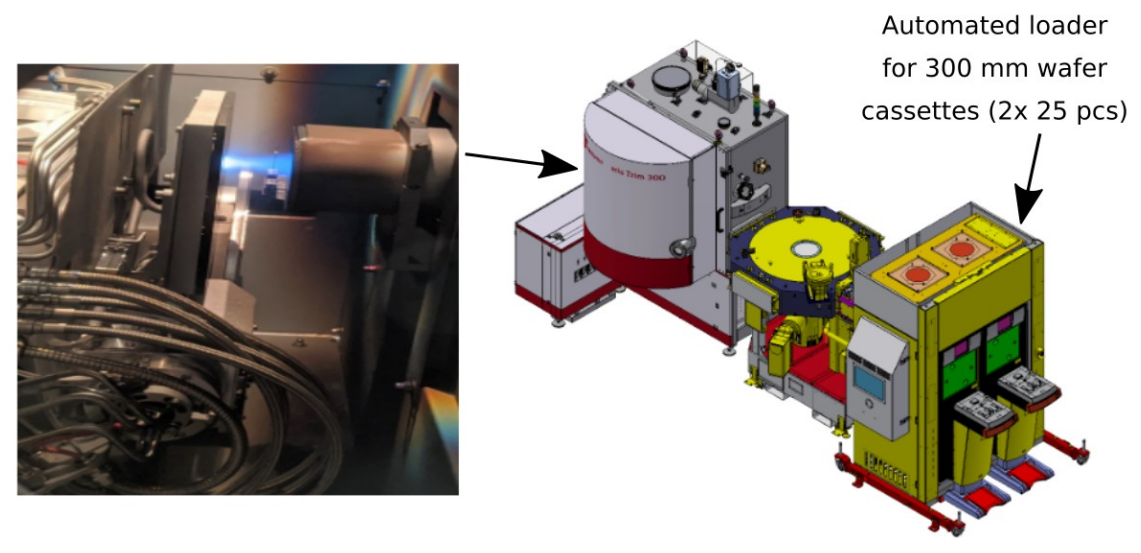

Figure 6. (Left) Ion beam inside of the processing chamber. (Right) Rendered drawing of a $300 \mathrm{~mm}$ IBF system.

\section{PREPARATION FOR FLIGHT/MASS PRODUCTION}

For the Athena flight production about 150,000 mirror plates will need to be processed, of which about 90,000 will end up in the flight model. All production equipment will need to be reliable and stable enough for a throughput of about 320 SPO plates per day in order to produce two mirror modules per day, as required to meet the schedule of Athena. This means that in parallel to further improving performance and effective area of the optics, we are also working on demonstrating all mass production aspects, as required for the adoption of the Athena mission by ESA.

\subsection{INCREASING THE PLATE PRODUCTION RATE}

After producing the first inner, middle and outer radius SPO plates at Teledyne e2v in 2018, the need for a customized ribbing and dicing saw was highlighted. Ribbing and dicing is seen as a bottleneck process in plate manufacture from a throughput as well as cost perspective. In 2020, a dedicated SPO plates dicing and ribbing process has been implemented at Teledyne e2v. For this, the $300 \mathrm{~mm}$ fully automated dicing machine shown in the left picture in Figure 7 has been selected and installed in the clean room at Teledyne e2v. 

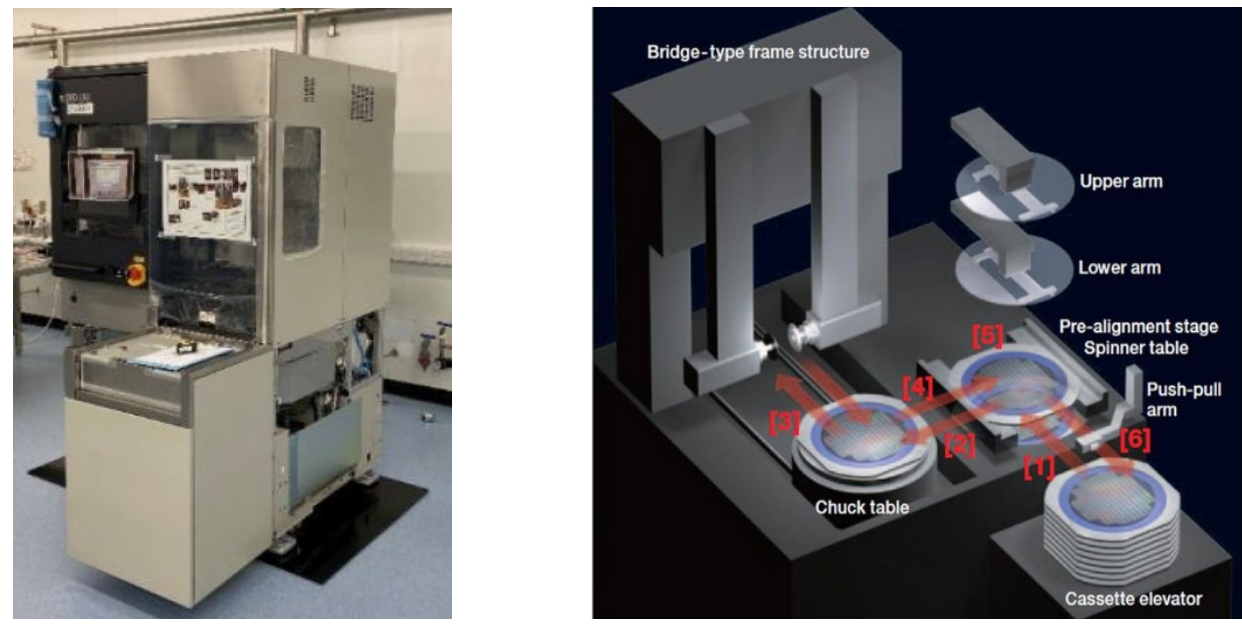

Figure 7. (Left) New dicing machine at Teledyne e2v. (Right) Dicing machine operation flow.

The dicing machine has a dual spindle setup, meaning that it can hold two dicing blades at once (either for double the cutting speed, or for two types of operations in one run: ribbing and dicing). It can also run unmanned, as the wafer loading/unloading is done automatically by a robot. The operation flow of the machine is depicted in the right image in Figure 7.

The flat, reflective side of SPO plates is patterned with a low and high density composite material in order to increase the $\mathrm{X}$-ray reflectivity. This patterning is realized by photolithography, where a photo-responsive polymer is selectively exposed through a photomask. To apply this photo-responsive polymer (photoresist), spin coating is traditionally used to obtain a coating of uniform thickness on top of round, flat wafers. Centrifugal forces ensure a uniform spread of a small volume applied to the center of the wafer. In contrast to traditional round wafers, SPO plates are radially asymmetric and have sharp (non-round) edges. This causes thickness non-uniformity issues and edge bead features when spin coating is used to apply the photoresist. The left picture in Figure 8 shows a $10 \mathrm{~nm}$-thick iridium coated SPO plate after lift-off using a spin-coating process for photoresist deposition. The edge bead effect can clearly be observed along the edges of the plate. In addition, SPO plates cannot be immobilized as required for spin coating. Vacuum suction cannot be applied due to the rib structure and mechanical clamping introduces photoresist edge features/defects.

The most obvious and readily available solution is to use spray coating to apply photoresist onto SPO plates. By generating micrometer-sized droplets, the SPO plate surface is provided with a coating of uniform thickness independent of surface or plate shape. Moreover, spray coating is not dependent on centrifugal forces, so SPO plates would not need to be immobilized. The right photograph in Figure 8 shows an immaculately patterned $10 \mathrm{~nm}$-thick iridium coated SPO plate after lift-off using a spray-coating process for photoresist deposition.
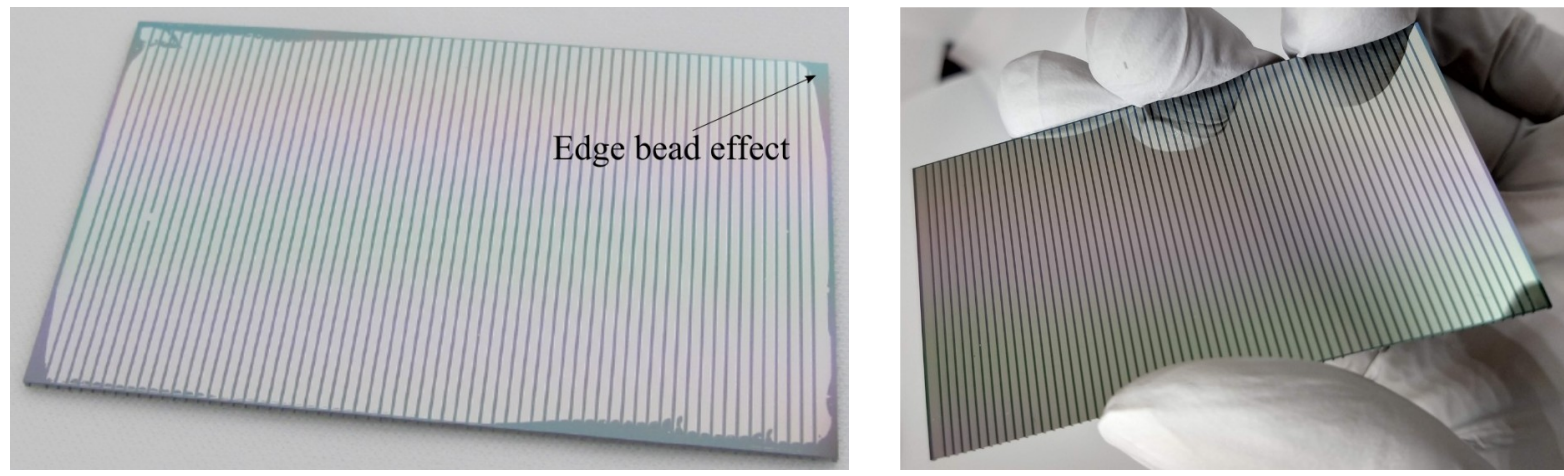

Figure 8. (Left) spin coated photoresist patterned coated SPO plate after lift-off. (Right) spray coated photoresist patterned coated SPO plate after lift-off.

A dedicated industrial $300 \mathrm{~mm}$ spray coating machine is currently being commissioned at Micronit B.V. (see Figure 9) The machine will make it possible to produce photoresist spray-coated SPO plates in larger quantities of about 90 SPO 
plates for outer and middle radius and forty-five for inner radius per hour (compared to previously six SPO plates per hour), The throughput required for Athena flight production and they will also be of consistent quality. The bottom picture in Figure 9 shows the reflective side of a SPO plate with applied negative photoresist. The thickness uniformity of the photoresist has been characterized to better than five percent. No edge bead effect is visible.
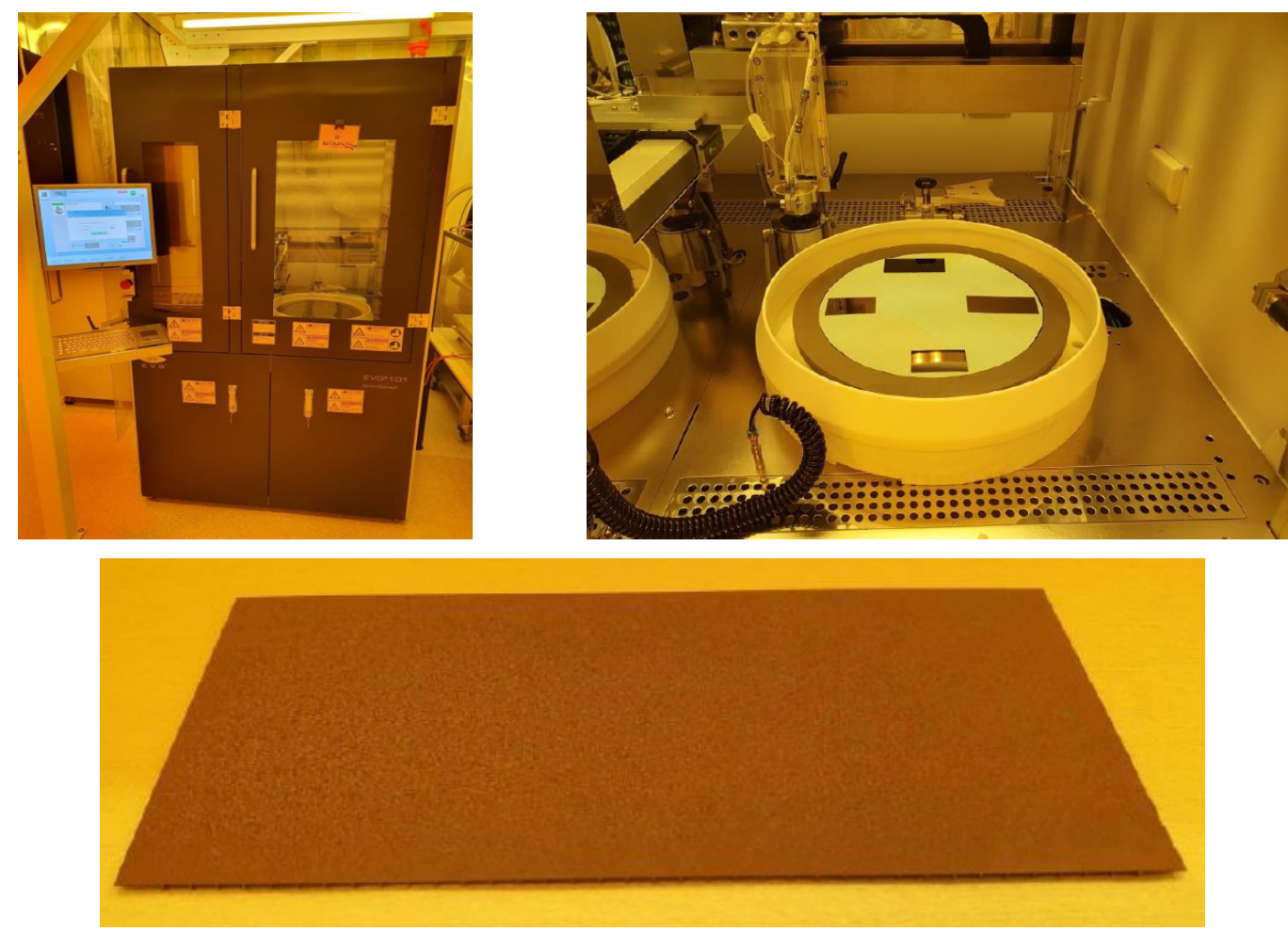

Figure 9. (Top left) New spraycoater installed inside of clean room at Micronit. (Top right) SPO plates on $300 \mathrm{~mm}$ wafer chuck inside of spraycoater. (Bottom) SPO plate spray coated with negative photoresist.

The currently used plate-packaging method (see left photograph in Figure 10) consists of wrapping individual SPO plates in a polyester cloth and encasing them in a membrane box. This method deteriorates the quality and yield of SPO plates after shipment, because the cloth leaves particles on the optical surface of SPO plates. The cloth also damages the surface and leaves behind residues. In addition, this method is not suitable for high-volume packaging and transport, because it is time consuming.

We designed, prototyped and produced a new packaging method to improve SPO plate quality, yield and SPO plate transport efficiency. This packaging design is based on a conventional and commercially available $200 \mathrm{~mm}$ shipment container. The geometry of the container is utilized to hold the SPO plate inserts in position as shown in the right photograph in Figure 10. The new packaging system is designed to minimize any possible contact of plates with other plates, limit contact with packaging material in general and limit plate handling time. We started to use this new packaging on small shipment quantities to collect sufficient information about its usability and plan to retire the membrane boxes before the end of 2021. 

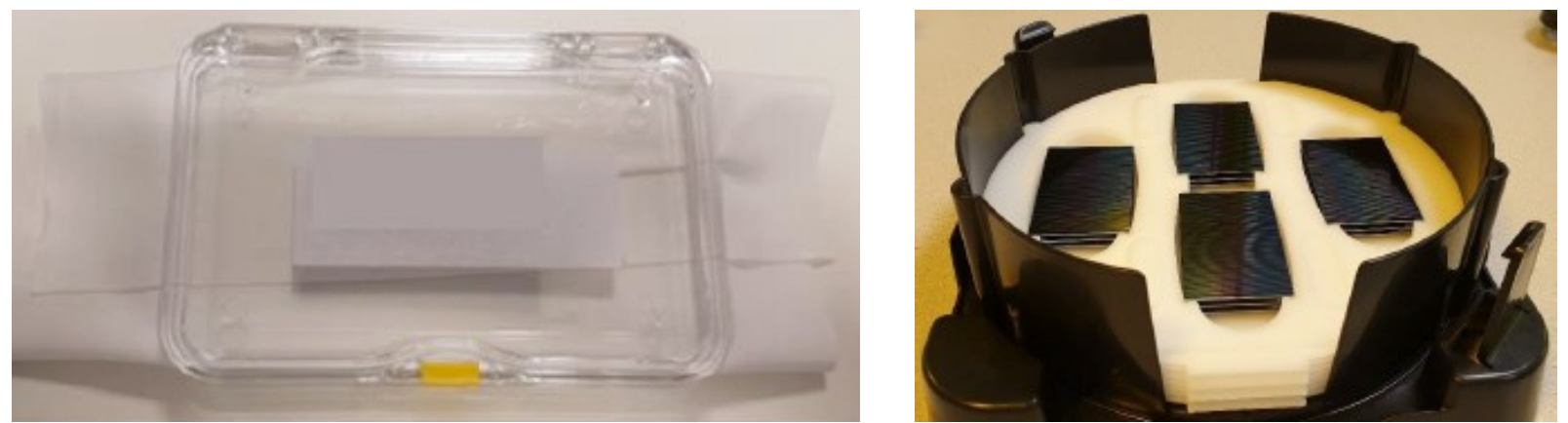

Figure 10. (Left) current packaging method. (Right) new packaging method.

\subsection{IMPROVING THE PLATE INCOMING INSPECTION}

Currently, SPO plate inspection is performed manually by operators. As this way of inspection is not suitable for Athena flight production in terms of throughput and price, a dedicated fully automated so-called plate inspection bench (PIB) for incoming inspection of SPO plates is being developed to increase inspection speed and further reduce particulate contamination. The system is being set up beside cosine's new fully automated wetbench inside of the clean room.

The PIB will feature automated unloading and loading of SPO plate containers including an identification code scanner and five possible inspection stations where the following are planned

- Total thickness variation (TTV) measurements

- Dimensional measurements

- Particulate contamination measurements

- Bonding station

The automated handling of SPO plates is now being tested extensively in order to ensure minimal contamination during plate handling and reliable operation of this process step. First fully automated unloading and loading of SPO plates from and into a container respectively, has been performed successfully. We are planning to have the first version of the PIB including automated TTV measurements operational before the end of 2021. Additional inspection stations are being developed in parallel and will be added to the system in the course of 2022.

\subsection{IMPROVING THE PLATE COATING PROCESS}

The mirror plate coating process takes place at cosine using a high-throughput magnetron sputtering system [15]. It also features a plasma cleaning system [18]. This year, the coating machine has been upgraded with the following components. The upgraded system is shown in Figure 11.

- A third magnetron to enable deposition of low-Z materials. Now, three different materials can be sputtered: iridium (high-Z), chromium (adhesion and stress reduction) and either boron carbide, silicon carbide or carbon (low-Z). With this upgrade, we will also be able to deposit multilayer coatings on SPO plates.

- A bake-out system including heat shielding and a chiller in order to minimize residual water inside the vacuum chamber. This is crucial for achieving stoichiometric boron carbide.

- An additional turbo pump to lower base pressure and reduce pump-down time by a factor of two.

A dedicated activity is running together with the Danish Technical University (DTU) to streamline the coating mass production process. The first goal of a stable baseline for producing large quantities of clean and bondable iridiumcoated SPO plates was achieved in June 2021 [16]. As a next step, we are proceeding with developing a stable low-Z material coating (material candidates: boron carbide, silicon carbide and carbon) on top of the patterned iridium-coated SPO plates with emphasis on it surviving all process steps involved in making SPO [19]. The plan is to achieve this goal before the end of 2021 so that development of multilayer coatings can commence at the beginning of 2022. 

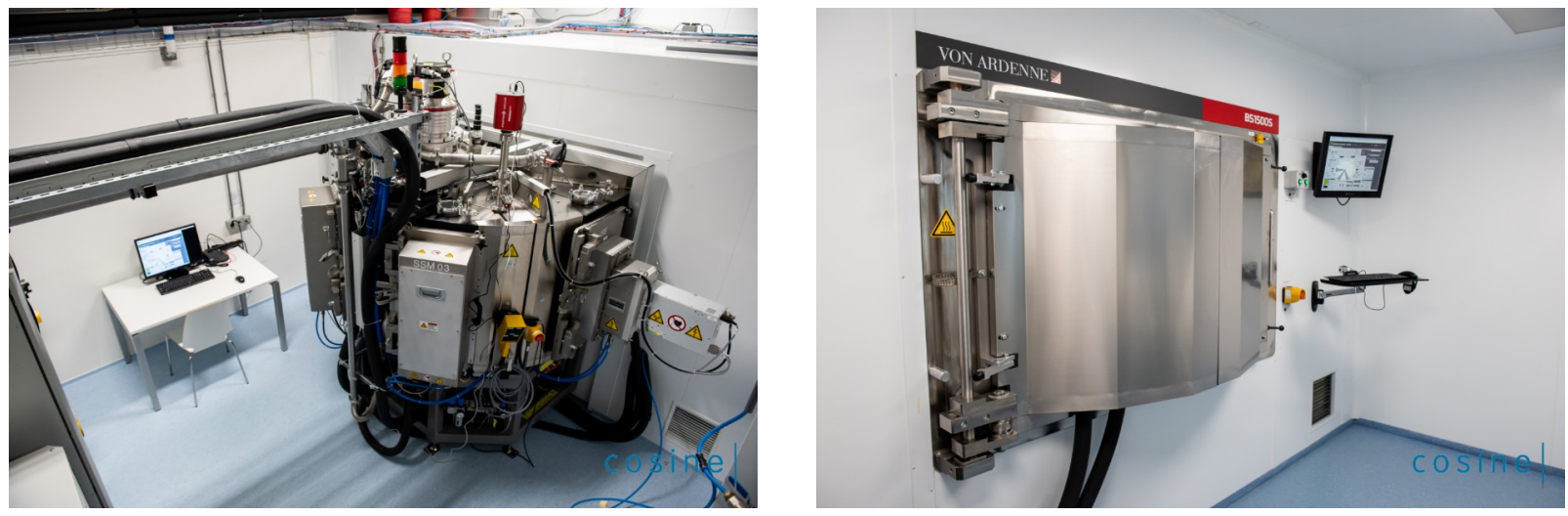

Figure 11. Upgraded coating machine BS1500S at cosine. (Left) Back side and (Right) clean room side of the system.

\subsection{IMPROVING THE PLATE LIFT-OFF PROCESS}

The cleaning of SPO plates prior to stacking has been industrialized and further automated. An industrial fully automated wetbench with handling robot has been installed and has been operational at cosine since the beginning of 2021 (see left photograph in Figure 12). This new wetbench also includes an industrial lift-off bath. During production, SPO plates loaded in cassettes are picked up by the handling robot (see right photograph in Figure 12), and are automatically run through lift-off processing and SC-1 cleaning. The system includes chemical concentration monitors for quality assurance purposes and to achieve a reproducible cleaning process.

Before implementing the industrial and automated lift-off bath in the production process, we were only able to lift-off 12 SPO plates in about 40 minutes using so-called lift-off containers and beakers. For Athena flight production, this wouldn't have been a possibility as a full coating run of 350 outer radius SPO plates would take about $19 \mathrm{~h}$ of lift-off processing time. In addition to throughput, the risk of particle contamination on the reflective side of SPO plates due to sedimentation of lifted-off coating flakes in beakers is high. Therefore, a more cost-efficient alternative was to include a lift-off bath in the new wetbench such that the process of lift-off and SC-1 cleaning can be performed in one go. This dedicated lift-off bath increases throughput by a factor of four compared to the previously run manual lift-off process and reduces risk of contamination.
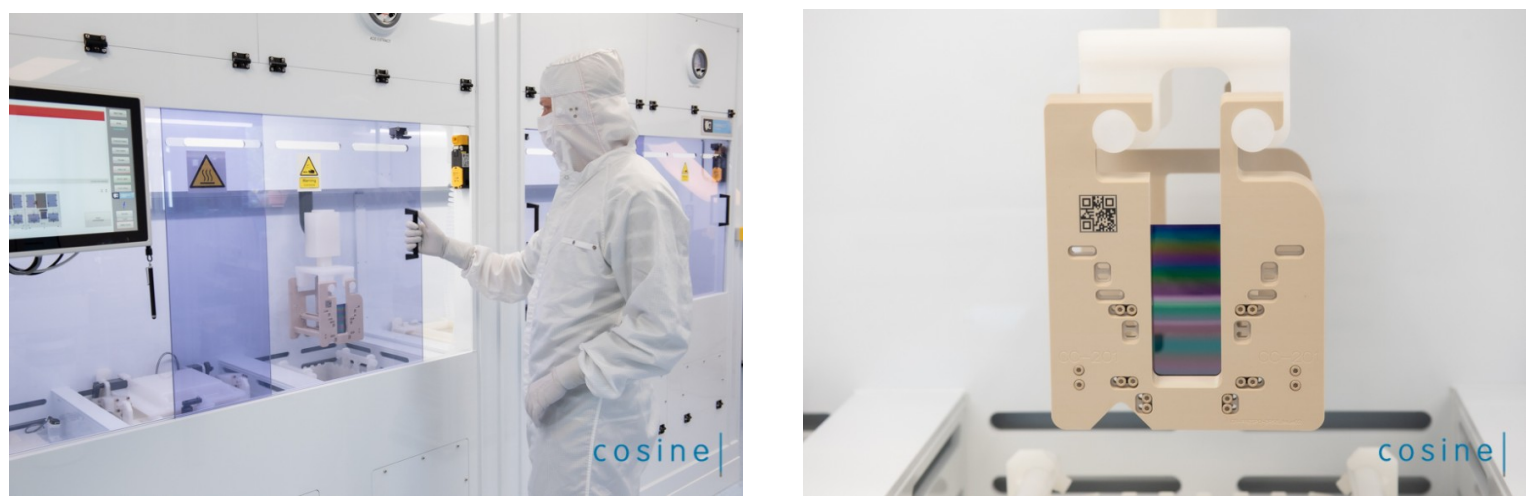

Figure 12. The newly installed and operational fully automated cosine wetbench (left), which includes an automated lift-off bath for post coating resist removal. The right photo shows a container inside of the wetbench holding SPO plates.

\section{CONCLUSIONS}

In this paper, we have summarized the current state-of-the-art in Silicon Pore Optics plate manufacturing technology. A customized dicing process is used to obtain ribbed square shaped SPO plates from $300 \mathrm{~mm}$ double-sided polished monocrystalline silicon wafers. New SPO plate types featuring larger pores are being developed and implemented in order to improve optical performance and increase effective area. Customized equipment is used to fabricate SPO plates of the correct geometry, and industry-standard wet-chemical processes to ensure bondable surfaces. In summary, a 
process flow is being developed to manufacture stackable SPO mirror plates with accurate control of the wedge angle, which is suitable to meet the requirements of Athena. With this combination of standard wafer processes and standard equipment, it will be possible to manufacture the required $\sim 150,000$ SPO plates for Athena in a cost-effective way.

In view of further process improvements and Athena flight/mass production, ion beam figuring processing is being developed in order to further improve wedge accuracy and to reduce recurring cost and complexity of the SPO plate production process by performing processing on wafer level instead of on plate level. A dicing and ribbing process has been implemented at Teledyne e $2 \mathrm{v}$ by installing a fully automated dicing machine in their clean room. For improving the photoresist deposition process and reducing edge bead effect, a spraycoater has been installed and is being commissioned at Micronit B.V. A dedicated so-called plate inspection bench is being developed to increase SPO plate inspection speed and improve particulate contamination. In addition, a new fully automated wetbench for industrial lift-off processing and SC-1 cleaning has been installed at cosine and has been implemented in SPO production operations. The coating machine has recently been upgraded with a third magnetron to enable the deposition of three different materials, a bakeout system to minimize residual water inside of the vacuum chamber and a second turbo pump to lower base pressure and reduce pump-down time. As part of a dedicated coating development activity, the goal of a stable baseline for producing large quantities of clean and bondable iridium-coated SPO plates has been achieved. As a next step, the development of low-Z material coating (material candidates: boron carbide, silicon carbide and carbon) on top of patterned iridium-coated SPO plates will commence in August 2021.

\section{REFERENCES}

[1] Bavdaz, M. et al., "Progress at ESA on high-energy optics technologies", Proc. SPIE 5168, 136-147 (2004).

[2] Beijersbergen, M. et al., "Silicon pore optics: novel lightweight high-resolution X-ray optics developed for XEUS", Proc. SPIE 5488, 868-874 (2004).

[3] Kirpal, N. et al., "The Hot and Energetic Universe: A White Paper presenting the science theme motivating the Athena+ mission", arXiv e-prints arXiv:1306.2307 (2013).

[4] Barret, D. et al., "The Athena X-ray Integral Field Unit (X-IFU)", Proc. SPIE 9905, id. 99052F 41 pp. (2016).

[5] Rau, A. et al., "The Hot and Energetic Universe: The Wide Field Imager (WFI) for Athena+", arXiv eprints arXiv:1308.6785.

[6] Wille, E., et al, "Silicon pore optics manufacturing plan and schedule for ATHENA", Proc. of SPIE Vol. 10699, 106993L (2018)

[7] Bavdaz, M. et al., "ATHENA x-ray optics developments and accommodation", Proc. SPIE 11822, Optics for EUV, X-Ray, and Gamma-Ray Astronomy X, 1182205 (2 August 2021).

[8] Ferreira, I. et al., "ATHENA: phase A study status and optics/instrument accommodation", Society of PhotoOptical Instrumentation Engineers (SPIE) Conference Series 11119-27 (Aug 2019).

[9] Collon, M. J. et al., “”, Proc. SPIE 11822, Optics for EUV, X-Ray, and Gamma-Ray Astronomy X, 1182204 (2021).

[10] Smith, R. K., "Arcus: the soft x-ray grating explorer", in Society of Photo-Optical Instrumentation Engineers (SPIE) Conference Series 11118-31 (Aug 2019).

[11] Keek, L. et al., "Stacking of mirrors for silicon pore optics", in Society of Photo-Optical Instrumentation Engineers (SPIE) Conference Series 11119-OH (Aug 2019).

[12] Barrière, N. M. et al., "Assembly of confocal silicon pore optic mirror modules", in Society of Photo-Optical Instrumentation Engineers (SPIE) Conference Series 11119-18 (Aug 2019).

[13] Vacanti, G. et al., "Measuring Silicon Pore Optics", in Society of Photo-Optical Instrumentation Engineers (SPIE) Conference Series 11119-17 (Aug 2019).

[14] Girou, D. et al., "Environmental testing of the Athena telescope mirror modules", Proc. SPIE 11822, Optics for EUV, X-Ray, and Gamma-Ray Astronomy X, 1182220 (2021).

[15] Massahi, S., et al, "Installation and commissioning of the silicon pore optics coatings facility for the Athena mission", Proc. SPIE 11119, Optics for EUV, X-Ray, and Gamma-Ray Astronomy IX, 111190F (2019).

[16] Svendsen, S., et al, "Compatibility of iridium thin films with the silicon pore optics technology for Athena", Proc. SPIE 11822, Optics for EUV, X-Ray, and Gamma-Ray Astronomy X, 118220C (1 August 2021).

[17] Barrière, N. M., et al, "Assembly of confocal silicon pore optic mirror modules", Proc. SPIE 11822, Optics for EUV, X-Ray, and Gamma-Ray Astronomy X, 1182215 (2021). 
[18] Girou, D., et al, "Plasma etching for the compatibility of thin film metallic coatings and direct bonding of silicon pore optics", Journal of Applied Physics. 128, 9, 7 p., 095302.

[19] Massahi, S, et al., "The effect of deposition process parameters on thin film coatings for the Athena X-ray optics", Proc. SPIE 11822, Optics for EUV, X-Ray, and Gamma-Ray Astronomy X, 118220B (1 August 2021).

[20] Vacanti, G. et al., "On the optical design of a large X-ray mirror based on silicon pore optics", Proc. SPIE 11822, Optics for EUV, X-Ray, and Gamma-Ray Astronomy X, 118220E (1 August 2021).

[21] Ferreira, D. D. M., et al. "Design, development, and performance of X-ray mirror coatings for the ATHENA mission”, Proc. SPIE 10399, Optics for EUV, X-Ray, and Gamma-Ray Astronomy VIII [1039918] (2017). 